\title{
Current and emerging treatment strategies for Duchenne muscular dystrophy
}

\author{
This article was published in the following Dove Press journal: \\ Neuropsychiatric Disease and Treatment \\ 22 July 2016 \\ Number of times this article has been viewed
}

Jean K Mah

Department of Pediatrics and Clinical Neurosciences, Cumming School of Medicine, University of Calgary, Calgary, Alberta, Canada
Correspondence: Jean K Mah Alberta Children's Hospital, 2888 Shaganappi Trail NW, Calgary,

Alberta, Canada T3B 6A8

Tel +l 4039552296

Fax + I 4039557649

Email jean.mah@albertahealthservices.ca
Abstract: Duchenne muscular dystrophy (DMD) is the most common form of muscular dystrophy in childhood. It is caused by mutations of the $D M D$ gene, leading to progressive muscle weakness, loss of independent ambulation by early teens, and premature death due to cardiorespiratory complications. The diagnosis can usually be made after careful review of the history and examination of affected boys presenting with developmental delay, proximal weakness, and elevated serum creatine kinase, plus confirmation by muscle biopsy or genetic testing. Precise characterization of the DMD mutation is important for genetic counseling and individualized treatment. Current standard of care includes the use of corticosteroids to prolong ambulation and to delay the onset of secondary complications. Early use of cardioprotective agents, noninvasive positive pressure ventilation, and other supportive strategies has improved the life expectancy and health-related quality of life for many young adults with DMD. New emerging treatment includes viral-mediated microdystrophin gene replacement, exon skipping to restore the reading frame, and nonsense suppression therapy to allow translation and production of a modified dystrophin protein. Other potential therapeutic targets involve upregulation of compensatory proteins, reduction of the inflammatory cascade, and enhancement of muscle regeneration. So far, data from DMD clinical trials have shown limited success in delaying disease progression; unforeseen obstacles included immune response against the generated mini-dystrophin, inconsistent evidence of dystrophin production in muscle biopsies, and failure to demonstrate a significant improvement in the primary outcome measure, as defined by the 6-minute walk test in some studies. The long-term safety and efficacy of emerging treatments will depend on the selection of appropriate clinical end points and sensitive biomarkers to detect meaningful changes in disease progression. Correction of the underlying mutations using new gene-editing technologies and corticosteroid analogs with better safety profiles offers renewed hope for many individuals with DMD and their families.

Keywords: Duchenne muscular dystrophy, emerging treatment, standard of care, review

\section{Introduction - case illustration}

A 3-year-old boy is referred for evaluation of developmental delay. He was born after an unremarkable pregnancy at term, with no complications. His development was normal during the first year. Although he is generally healthy and has good muscle bulk, he did not walk until after his second birthday. He is shy and he currently speaks in single words only. His examination is normal apart from calf hypertrophy and proximal weakness. He struggles to get up from the floor, and he is unable to run, jump, or climb stairs on his own. Initial investigation shows an elevated serum creatine kinase $(\mathrm{CK})$ of 35,000 U/L (normal <200 U/L). Molecular genetic testing reveals an out of frame mutation in the $D M D$ gene. His parents want to know more about the diagnosis and available treatment options. 


\section{Background on Duchenne muscular dystrophy}

Duchenne muscular dystrophy (DMD) is a genetic muscle disorder that affects one per 3,500-5,000 live-born males; it is the most common type of muscular dystrophy in childhood. ${ }^{1,2}$ It is caused by mutations of the $D M D$ gene, located on chromosome Xp21, which encodes for dystrophin, a $427 \mathrm{kDa}$ protein that is expressed at the muscle sarcolemma. The absence of dystrophin destabilizes the muscle membrane, leading to the clinical features of motor developmental delay, calf hypertrophy, joint contractures, and progressive muscle weakness in affected boys, with markedly elevated serum CK that reflects ongoing muscle damage. In addition, boys with DMD may have a variable degree of speech delay, learning disability, and/or cognitive impairment. ${ }^{3,4}$ Progressive muscle degeneration eventually leads to loss of independent ambulation by early adolescence, scoliosis, cardiomyopathy, respiratory insufficiency, and reduced life expectancy, with death occurring before the third or fourth decade of life due to cardiorespiratory complications, according to recent DMD natural history studies. ${ }^{5,6}$

The $D M D$ gene is one of the largest known human genes. It contains 79 exons, which include an actin-binding domain at the $\mathrm{N}$-terminus, 24 spectrin-like repeat units, a cysteine-rich dystroglycan binding site, and a C-terminal domain. ${ }^{78}$ The extremely large size of the gene contributes to a complex mutational spectrum, with $>7,000$ different mutations and a high spontaneous mutation rate. ${ }^{9}$ Approximately two-thirds of cases are maternally inherited; the remaining one-third occurs as a result of spontaneous mutations. ${ }^{10}$ Large (one or more exons) deletions account for approximately two-thirds of all DMD mutations; the rest are due to duplications and small deletions, insertions, point mutations, or splicing mutations. ${ }^{11,12}$ The severe phenotype associated with DMD is most often caused by outof-frame mutations, with complete loss of the dystrophin protein. ${ }^{13,14}$ In-frame mutations that allow for the synthesis of an internally truncated but partially functional protein are associated with a milder and more variable phenotype known as Becker muscular dystrophy or X-linked dilated cardiomyopathy; exceptions to the reading frame hypothesis occur in $<10 \%$ of all $D M D$ mutations. ${ }^{10,15}$ Disease severity is also affected by other genetic modifiers distinct from the $D M D$ gene, including single nucleotide polymorphism of the latent transforming growth factor-beta (TGF- $\beta$ ) binding protein 4 (LBP4) gene and osteopontin, encoded by the secreted phosphoprotein 1 (SPPI) gene; both genes appear to influence disease progression in DMD by modifying the age at loss of independent ambulation, the age at onset of dilated cardiomyopathy, and the clinical response to corticosteroid treatment. ${ }^{16-18}$

Dystrophin is an integral part of the dystrophinassociated glycoprotein complex. It is in close association with other cytoskeletal proteins, including F-actin via its $\mathrm{N}$-terminus and part of the rod domain; it also binds to dystroglycan via its cysteine-rich domain and to dystrobrevin and syntrophin via the C-terminal domain. ${ }^{19}$ Thus, dystrophin provides structural stability to the skeletal muscle by connecting the sarcolemma and the basal lamina of the extracellular matrix to the inner cytoskeleton. It is also essential for cell survival via its transmembrane signaling function and modulation of vasomotor response to physical activity. ${ }^{20}$ Three isoforms of dystrophin are derived from independent promoters in the brain, retina, and Purkinje cerebellar neurons; mutations in these tissue specific isoforms of dystrophin likely contribute to the extramuscular manifestations of DMD, including cognitive, behavioral, and learning difficulties. ${ }^{19}$

Loss of dystrophin as a result of $D M D$ gene mutations disrupts the dystrophin glycoprotein complex, leading to increased muscle membrane fragility. A cascade of events including influx of calcium into the sarcoplasm, activation of proteases and proinflammatory cytokines, and mitochondrial dysfunction results in progressive muscle degeneration..$^{20-22}$ In addition, displacement of neuronal nitric oxide synthase contributes to tissue ischemia, increased oxidative stress, and reparative failure. ${ }^{23}$ Disease progression is characterized by increasing muscle necrosis, fibrosis, and fatty tissue replacement and a greater degree of fiber size variation seen in subsequent muscle biopsies. ${ }^{24}$

\section{Making a diagnosis of DMD}

The diagnosis of DMD can usually be made after a careful review of the clinical history, physical examination, and confirmation by additional investigations, including muscle biopsy and/or molecular genetic testing. ${ }^{3}$ A positive family history of DMD is not required, as approximately one-third of cases may occur as a result of spontaneous mutation. The presence of motor developmental delay with or without speech delay and muscle hypertrophy in a young boy should trigger the order of serum CK as an initial diagnostic screen for DMD, especially if the child also has signs of proximal muscle weakness, manifesting as an abnormal waddling gait, or a positive Gowers' sign (Figure 1). ${ }^{25}$ As shown in the case illustration earlier, the muscle enzymes as measured by serum CK are usually markedly elevated. Raised muscle enzymes in DMD also contribute 


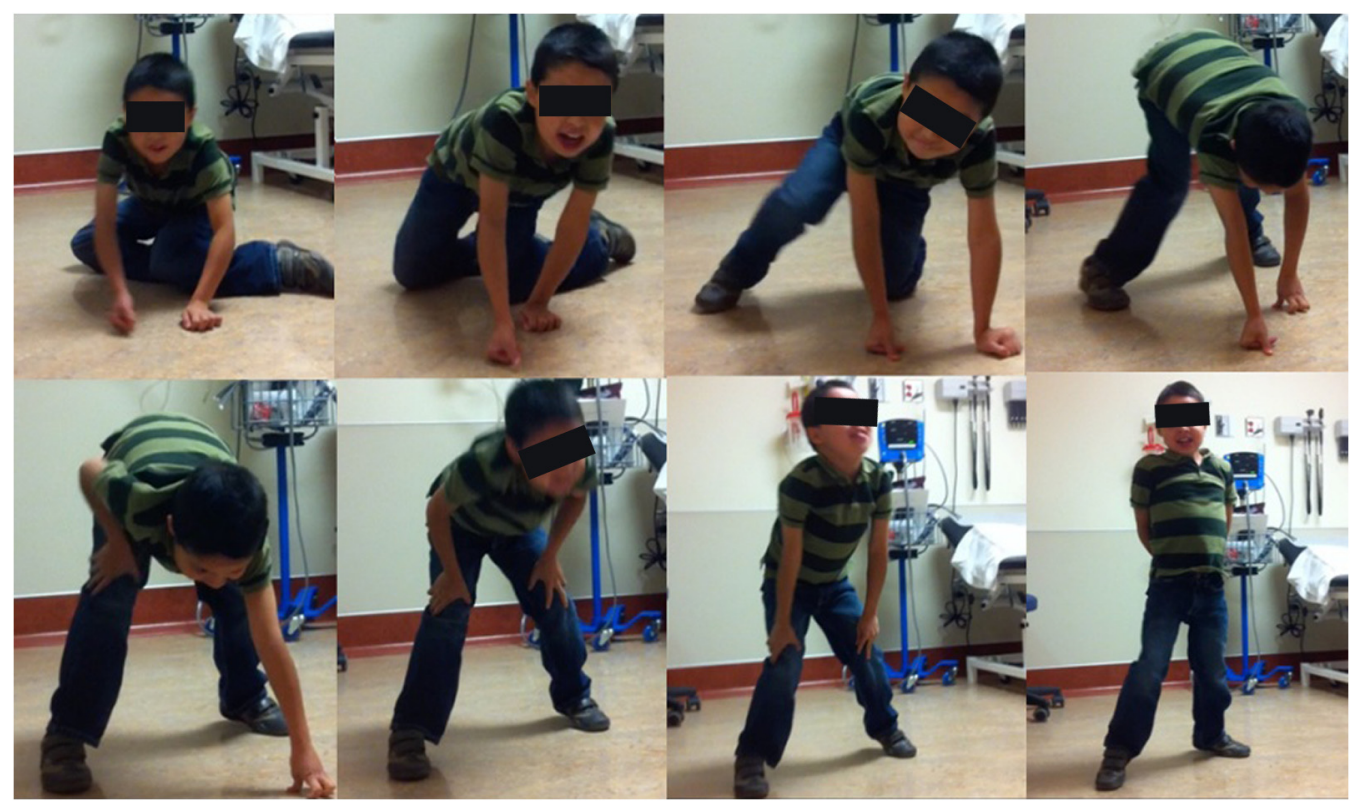

Figure I A young boy illustrates the typical Gowers' sign.

Notes: The maneuver consists of pushing on the floor, followed by climbing up on his legs to achieve a standing position, due to proximal muscle weakness.

to persistently high serum alanine and aspartate transaminase levels; in some cases, the diagnosis may be delayed due to initial investigations for suspected hepatic dysfunction.

Genetic testing for $D M D$ mutations includes multiplex polymerase chain reaction focusing on the most commonly deleted regions of the gene or other assays that interrogate all 79 exons, such as multiplex ligation-dependent probe amplification (MLPA) or comparative genomic hybridization (CGH) microarray. ${ }^{12,26}$ If these diagnostic tests fail to identify the presence of a disease-causing deletion or duplication, complete gene sequencing is required to define the precise mutational event. A muscle biopsy can also be obtained for dystrophin immunostaining and extraction of RNA to produce complementary DNA and confirm a dystrophin mutation. The muscle biopsy typically shows a dystrophic process with ongoing muscle degeneration and regeneration; dystrophin immunostaining is usually absent or markedly reduced, except in rare revertant fibers. Using currently available diagnostic methods, it is possible to identify the mutations and confirm the clinical phenotypes in nearly all patients with dystrophinopathy. ${ }^{27}$

\section{Supportive treatment for DMD}

Identification of a specific mutation is important for accurate diagnosis, prognosis, and individualized treatment for affected boys with DMD, as well as genetic counseling for their families. ${ }^{28}$ Beyond realizing the severity of the diagnosis, parents live with uncertainty in anticipation of future losses and limitations that their children will experience, and anxiety as to how their children may react to those losses. For most parents, the demand of caring for their child with neuromuscular disease was disruptive to family life; the needs of the siblings, the spouse, and the primary caregiver tended to become secondary priorities. ${ }^{29}$ The stress caused by the cognitive, behavioral, and other psychosocial challenges related to DMD can sometimes exceed those associated with the physical aspects of the disease. ${ }^{30,31}$ Increased burden of care and emotional distress are also common among caregivers of adults with DMD. ${ }^{32}$ These realities underscore the need for assessment and support of the entire family. ${ }^{3}$ Family-centered care, timely referrals, and appropriate community support can help parents to become experts on their child's diagnosis and normalize their daily care routine (Table 1). ${ }^{33}$ Mothers who are confirmed carriers of dystrophin mutations will also require periodic health surveillance for possible cardiomyopathy, myalgia, and/or proximal muscle weakness. ${ }^{34}$

There is presently no cure for DMD. Current treatment strategies focus on optimizing growth and development, promoting well-balanced diet, participating in physical and recreational activity, and delaying the onset of secondary complications through ongoing medical and psychosocial support. ${ }^{35}$ Supportive interventions including timely treatment with corticosteroids, early afterload reduction for cardiomyopathy, aggressive management of heart failure, noninvasive positive pressure ventilation, and effective airway clearance strategies have contributed to prolonged 
Table I Current supportive strategies for DMD

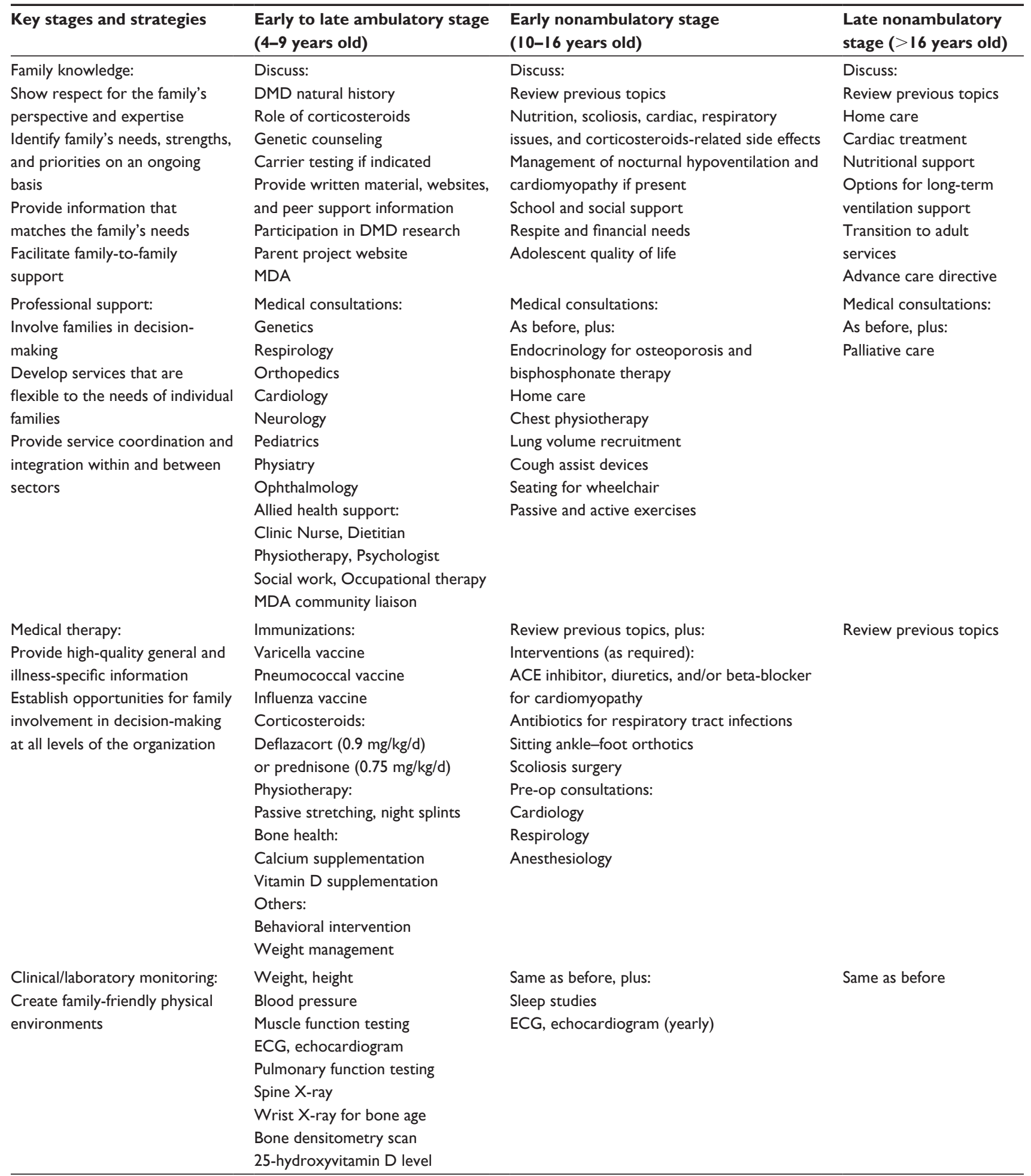

Note: Copyright @ 2010. Cambridge University Press. Adapted from McMillan HJ, Campbell C, Mah JK. Canadian Paediatric Neuromuscular Group. Duchenne muscular dystrophy: Canadian paediatric neuromuscular physicians survey. Can J Neurol Sci. 2010;37(2): 195-205. ${ }^{33}$

Abbreviations: DMD, Duchenne muscular dystrophy; MDA, muscular dystrophy association; ACE, angiotensin-converting enzyme; ECG, electrocardiography.

survival of individuals with DMD. The mean age of death from DMD increased from 14.4 years in the 1960 s to 25.3 years in the $1990 \mathrm{~s}$, with corresponding improvement in affected individuals' health-related quality of life. ${ }^{36-38}$

\section{Standard of care for DMD}

Recent publications from leading experts have provided comprehensive guidelines on the diagnosis and multidisciplinary management of DMD, including the use of 
corticosteroids. ${ }^{3,35,39,40}$ Historically, corticosteroids offered benefit to boys with DMD by stabilizing muscle strength and function, ${ }^{41,42}$ prolonging independent ambulation, ${ }^{43,44}$ and delaying the progression of scoliosis ${ }^{45}$ and cardiomyopathy. ${ }^{46}$ Continued treatment after loss of independent ambulation has also been shown to be beneficial. ${ }^{47,48}$ On the basis of available literature and clinical experience, current clinical practice guidelines strongly endorse the consideration of corticosteroid therapy for all DMD patients, starting at the early ambulatory stage of the disease. ${ }^{3,49}$ Daily oral prednisone $(0.75 \mathrm{mg} / \mathrm{kg})$ or deflazacort $(0.9 \mathrm{mg} / \mathrm{kg})$ is generally recommended as a disease-modifying treatment for DMD; intermittent steroids dosing schedule (10 days on/10 days off or high dose weekends only) are less commonly prescribed..$^{50}$ Prednisone and deflazacort are currently being studied in a head-to-head fashion as part of the FOR-DMD (NCT01603407) clinical trial; the results will hopefully determine the optimum corticosteroid regimen for DMD.

Common steroid-related side effects include short stature, obesity, cataracts, and skeletal fractures. ${ }^{44,51}$ In particular, approximately one-third of boys with DMD may develop vertebral compression fractures due to long-term corticosteroid use, progressive muscle weakness, impaired vitamin D and calcium absorption, and immobilization. Regular physical activity, calcium-enriched diet, optimization of vitamin D, and periodic assessments including lateral spine X-ray and bone density by dual energy X-ray absorptiometry scan are recommended as part of bone health management. ${ }^{35}$ Bisphosphonates are generally reserved for those with symptomatic vertebral compression and/or recurrent fragility fractures in the extremity, in association with persistent or multiple bone health risk factors $;{ }^{35}$ however, the long-term efficacy of bisphosphonate therapy for boys with DMD remains limited. ${ }^{52,53}$ Alternative treatments including denosumab and recombinant parathyroid hormone have not been formally evaluated in DMD. ${ }^{54}$

Cardiac complications are common in DMD, including myocardial necrosis, conduction defects, and/or arrhythmias. ${ }^{55,56}$ Progressive cardiomyopathy is one of the leading causes of mortality in DMD. ${ }^{36,57}$ Common electrocardiography (ECG) abnormalities include sinus tachycardia, tall R waves in V1, deep Q waves in the inferolateral leads, ST depression, prolonged QT interval, and increased QT dispersion. ${ }^{58}$ Echocardiographic evidence of structural heart disease in DMD patients includes left ventricular hypertrophy, regional wall motion abnormalities, dilation of the cardiac chambers, valvular abnormalities, and left ventricular systolic dysfunction..$^{59,60}$ Despite the high prevalence of cardiac disease, most affected individuals are asymptomatic due to their low physical capability; ${ }^{61}$ the diagnosis and treatment of DMD-related cardiomyopathy were often delayed. ${ }^{62}$ According to the 2010 DMD guidelines, baseline assessment including ECG and echocardiogram should be performed at diagnosis, with reassessments at least every 2 years and then annually after 10 years of age. ${ }^{35}$ However, echocardiograms may be technically difficult in DMD due to the development of progressive scoliosis, chest wall deformities, and respiratory insufficiency, thus limiting the utility of echocardiograms among patients with more advanced stages of the disease.

Increasingly, cardiac magnetic resonance imaging (MRI) has been used for the surveillance of myocardial dysfunction in DMD, especially in combination with gadolinium. ${ }^{63}$ Using late gadolinium enhancement, cardiac MRI may detect early myocardial fibrosis, in the absence of any overt echocardiographic abnormalities; ${ }^{64}$ however, young children (especially $<6$ years old) or those with significant cognitive or behavioral issues may not be able to tolerate the procedure without sedation. Early use of cardioprotective treatment including angiotensin-converting enzyme (ACE) inhibitors or beta-blocker may help delay the progression of cardiomyopathy. ${ }^{35,58}$ The addition of eplerenone to ACE inhibitors can also attenuate the decline in left ventricular systolic function. ${ }^{65}$ According to a recent DMD working group, new cardiac guidelines will soon be available to address the expanded use of cardiac MRI, the use of myocardial strain analysis and other advanced echocardiographic imaging techniques, and the need for early initiation of anti-heart failure regimen for the treatment of DMD-related cardiomyopathy. ${ }^{63}$

Individuals with DMD are also at increasing risk of respiratory complications due to progressive decline in respiratory muscle function. ${ }^{66,67}$ Signs of respiratory insufficiency include ineffective cough, recurrent chest infection, nocturnal hypoventilation, sleep disordered breathing, and eventually daytime respiratory failure. ${ }^{36,57}$ Regular pulmonary function testing is needed to monitor for early signs of respiratory insufficiency and to optimize treatment. ${ }^{35}$ The initial treatment for nocturnal hypoventilation in DMD patients includes noninvasive positive pressure ventilation by nasal prongs or face mask to improve sleep quality, decrease daytime sleepiness, enhance gas exchange, and delay the decline in the pulmonary function. ${ }^{68}$ Additional supportive strategies include chest physiotherapy, mechanical insufflation-exsufflation, and/or lung volume recruitment exercises to improve lung compliance and prevent atelectasis. ${ }^{69,70}$ The combination of noninvasive positive pressure ventilation, assisted airway 
clearance, mechanical cough assistance, and other respiratory supportive strategies allows DMD patients to live beyond their third decade of life..$^{71}$

The natural history of DMD includes increasing joint contractures and scoliosis as a result of progressive weakness, immobility, muscular imbalance, and fibrotic replacement in muscle tissue. ${ }^{35}$ The use of corticosteroids is associated with prolonged independent ambulation, delayed onset of scoliosis, and reduced need for spinal surgery. ${ }^{72}$ Affected individuals should be instructed to do active, active-assisted, and/or passive stretching exercise daily. Night splints can be worn to help minimize heel cord contractures, and serial casting may also be considered for short periods of time during the ambulatory phase of DMD. ${ }^{35}$

Routine health surveillance and growth monitoring are important for all pediatric DMD patients. Optimal nutritional status, as defined by weight or body mass index between the 10 th and the 85 th percentiles for age, based on national growth charts, should be encouraged. ${ }^{35}$ Referral to dietitian and formal feeding assessments may be indicated, particularly for those with bulbar symptoms or advanced stage of DMD. ${ }^{73}$ Other anticipatory guidance includes regular trivalent inactivated influenza and 23-valent pneumococcal polysaccharide vaccinations, in addition to routine childhood immunizations. As well, assessment for wheelchair, lifts, and other adaptive technology should be included as part of the comprehensive treatment plan. ${ }^{3,35}$

\section{Therapeutic strategies for DMD}

Recent scientific advances have led to new disease-modifying treatments for many neuromuscular diseases including DMD. ${ }^{74-76}$ Identification of coordination centers and patients eligible for specific DMD trials has been greatly facilitated by the establishment of TREAT-NMD and other international DMD disease registries. ${ }^{15}$ Regularly updated information about DMD clinical trials is available at https://www.ClinicalTrials.gov. A significant proportion of the active studies are enrolling participants by invitation only; as well, many of the studies listed are either Phase I safety or smaller Phase II pilot studies, with a fewer number of Phase III double-blind randomized trials. The main therapeutic strategies include, 1) gene replacement or other genetic therapies linked to specific mutations to restore dystrophin production; ${ }^{77-79}$ 2) membrane stabilization and/or upregulation of compensatory proteins; ${ }^{80,81}$ and 3) reduction of the inflammatory cascade and/or enhancement of muscle regeneration (Table 2). ${ }^{82,83}$ Specific examples of emerging therapeutic strategies for DMD, including exon skipping and nonsense mutation suppression therapies, are briefly summarized in the genetic therapies section.
Table 2 Emerging therapies for DMD

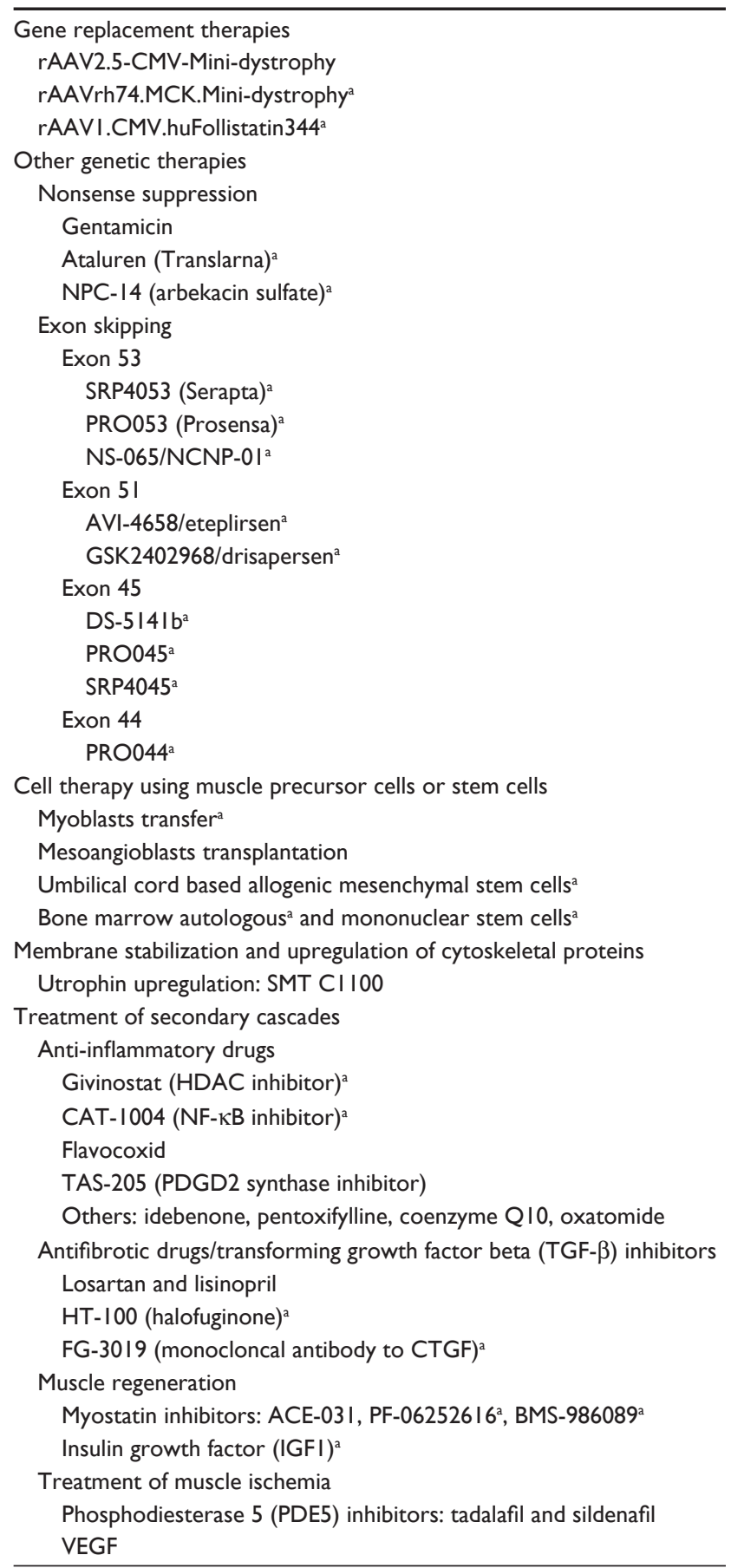

Notes: aActive or ongoing clinical trials, accessed on February 18, 2016 from www. clinicaltrials.gov.

Abbreviations: DMD, Duchenne muscular dystrophy; NF- $\mathrm{KB}$, nuclear factorkappa B; TGF- $\beta$, transforming growth factor beta; CTGF, connective tissue growth factor; ACE, angiotensin-converting enzyme; IGF, insulin growth factor; PDE5, phosphodiesterase 5; VEGF, vascular endothelial growth factor.

\section{Genetic therapies}

\section{Dystrophin gene replacement using virus vectors}

Previous attempts to develop gene therapy for DMD have been complicated by the enormous size of the dystrophin gene. This was subsequently addressed by deleting selective regions of the dystrophin protein, leading to the generation of functional 
mini- and microdystrophins. Injection of adeno-associated viruses carrying microdystrophins into dystrophic canine model of DMD results in a striking improvement in the muscle histopathology. ${ }^{84}$ However, earlier attempts in six boys with DMD due to frameshift mutations failed to achieve successful transgene expression, in part due to an unexpected primed T-cell-mediated immune response to the generated mini-dystrophin seen in two of the participants. ${ }^{85}$ Additional clinical trials using recombinant adeno-associated viruses and more efficient vector delivery system to replace defective genes in DMD are currently in progress. ${ }^{86}$

\section{Exon skipping}

Exon skipping uses synthetic antisense oligonucleotide sequences to correct specific dystrophin gene mutations. It does so by inducing specific exons skipping during premessenger RNA (pre-mRNA) splicing of the dystrophin gene, resulting in restoration of the reading frame and partial production of an internally truncated protein, similar to the dystrophin protein expression seen in Becker muscular dystrophy. Antisense therapies that induce single or multiple exon skipping could potentially be helpful for the majority of dystrophin mutations. ${ }^{79}$

An earlier Phase I clinical trial of four boys with DMD using PRO051, a 2'-O-methyl-phosphorothioate oligoribonucleotide designed to skip exon 51 in dystrophin pre-mRNA, showed partial $(17 \%-35 \%)$ restoration of dystrophin after a single intramuscular injection into the tibialis anterior. ${ }^{87}$ This was followed by a Phase II study including weekly subcutaneous injections of PRO051, also known as drisapersen, up to $6 \mathrm{mg} / \mathrm{kg} /$ dose into 12 young DMD boys with a mean age of 9.2 years (range $5-13$ years). ${ }^{88}$ In addition to injection site reactions, drisapersen was associated with transient elevation of $\alpha 1$-microglubulinuria and variable proteinuria; a slight increase in dystrophin expression and a modest improvement in the mean 6-minute walk test (6MWT) distance of $35.2 \mathrm{~m}$ (SD $28.7 \mathrm{~m}$ ) were seen after a 3-month open-label extension treatment. ${ }^{88}$ Furthermore, a single subcutaneous injection of drisapersen at escalating doses for 20 nonambulatory boys aged 9-12 years with DMD was well tolerated, aside from transient proteinuria, fever, and acute inflammatory reactions seen in three participants given the $9 \mathrm{mg} / \mathrm{kg}$ dose.$^{89}$ However, a larger Phase III clinical trial involving 186 boys with DMD (NCT01254019) failed to show a significant difference in the 6MWT among participants on drisapersen versus placebo. ${ }^{90}$ In a subsequent Phase II study involving a younger (mean age of 7.3 years, range 5-11 years) cohort of 53 patients with DMD, boys receiving continuous drisapersen weekly for 25 weeks demonstrated a slight improvement in the 6MWT and increased expression of dystrophin; however, there was no significant difference in the 6WMT at week $49 .{ }^{91}$ Furthermore, results of formal muscle strength and other timed function tests did not differ between either continuous or intermittent drisapersen regimen versus placebo. ${ }^{91}$ Further data from the open-label extension study of drisapersen (NCT02636686) is pending.

Eteplirsen (AVI-4658) is a phosphoramidate morpholino oligomer designed specifically for exon 51 skipping. ${ }^{92,93}$ In a subsequent double-blind placebo-controlled trial involving 12 participants (age 7-12 years) for 24 weeks followed by an open-label extension study of eteplirsen at either $30 \mathrm{mg} / \mathrm{kg} / \mathrm{wk}$ or $50 \mathrm{mg} / \mathrm{kg} / \mathrm{wk}$, Mendell et $\mathrm{al}^{94}$ found encouraging results in a subset ( $\mathrm{n}=10$ ) of participants, with significant improvement in walking ability and stabilization in their clinical function, and histological evidence of de novo dystrophin production and restoration of the dystrophin-associated protein complex in the muscle biopsies. Two older twin boys lost ambulation due to rapid disease progression, and they were excluded from the modified intention-to-treat analysis. ${ }^{94}$ No significant adverse effects were noted after weekly treatment for $>3$ years following the open-label extension study. ${ }^{95}$ The clinical benefits of eteplirsen for DMD will be determined as part of a larger confirmation study that is currently underway (PROMOVI, NCT0225552). Other exon skipping trials involving exons $44,45,53$, and multiple exon skipping are planned. ${ }^{96,97}$

\section{Nonsense suppression therapy}

Approximately $10 \%-15 \%$ of DMD is caused by point mutations leading to a premature stop codon. ${ }^{11,15}$ Premature stop codons are nucleotide triplets within mRNA that signal the termination of protein translation by binding release factors and causing the ribosomal subunits to disassociate and release the shortened amino acid chain. This usually results in a loss of the functional protein, as critical parts of the amino acid chain are missing. Aminoglycosides and other nonsense mutation suppression agents bind to the ribosomal RNA subunits and impair the recognition of premature stop codon, thus allowing translation and production of a modified dystrophin protein. Earlier treatment trials with gentamicin showed mixed results, with additional caution regarding its long-term use due to potential renal- and oto-toxicity. ${ }^{98-100}$

Ataluren (also known as Translarna) is an orally bioavailable drug designed to overcome premature nonsense mutations. ${ }^{101}$ Early studies of ataluren showed that it was generally safe and well tolerated. ${ }^{102}$ Among 174 boys with DMD due to confirmed premature stop codon mutations, a double-blind placebo-controlled study for 48 weeks showed 
a marginally significant improvement in 6MWT for those receiving low-dose $(40 \mathrm{mg} / \mathrm{kg} / \mathrm{d})$ ataluren only; those on highdose $(80 \mathrm{mg} / \mathrm{kg} / \mathrm{d})$ treatment did not improve in their 6MWT when compared with placebo, and the results were attributed to ataluren's bell-shaped dose-response curve. ${ }^{103}$ Ataluren has received conditional approval by the European Medicines Agency since August 2014; ${ }^{104}$ results from the confirmatory trial (NCT02090959) is currently pending. Clinical trials involving other nonsense mutation suppression agents including arbekacin sulfate (NCT01918384) are being planned. ${ }^{105}$

\section{Cell therapy using muscle precursor cells or stem cells}

Earlier attempts with myoblasts transfer were unsuccessful due to a number of factors, including limited viability of the donor cells after transplantation and suboptimal response from the use of older immunosuppressive regimen. ${ }^{106}$ Even though a recent clinical trial showed that intra-arterial transplantation of human leukocyte antigen-matched sibling donor mesoangioblasts with better immunosuppression therapy was relatively safe and well tolerated, only a low level of donor DNA was found in the muscle biopsies, and no functional improvements were seen among the five boys with DMD posttransplant. ${ }^{107}$ New cell therapies including induced pluripotent stem cells offer the potential of yielding an unlimited supply of autologous stem cells; however, patient-derived induced pluripotent stem cells will need to be genetically corrected before transplantation, and the long-term safety of this approach remains undefined. ${ }^{108}$

\section{Membrane stabilization and upregulation of cytoskeletal proteins}

Compensatory upregulation of cytoskeleton proteins including utrophin, ${ }^{109}$ alpha-7-beta-1 integrin, ${ }^{110}$ biglycan, ${ }^{111}$ and sarcospan ${ }^{112}$ has been shown to stabilize the sarcolemma, in the absence of dystrophin in $m d x$ mice, with improvement seen in the muscle biopsies. SMT C1100 is an oral bioavailable molecule specifically designed to target the utrophin-A promoter to increase utrophin expression; both SMT C1100 and its related compounds SMT022357 were shown in vitro and in vivo experiments to increase the production of utrophin and reduce the dystrophic changes in the skeletal and cardiac muscles. ${ }^{113}$ Further clinical trials data related to SMT C1100 (NCT02056808 and NCT02383511) are currently pending.

\section{Treatment of secondary cascades}

\section{Anti-inflammatory drugs}

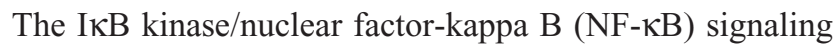
is persistently elevated in immune cells and regenerative muscle fibers in both animal models and patients with DMD. ${ }^{114}$ As well, activators of NF- $\mathrm{KB}$ such as tumor necrosis factor- $\alpha$ and interleukins 1 and 6 are upregulated in DMD muscles. Pharmacological inhibition of NF- $\mathrm{KB}$ using the NEMO-binding domain peptide resulted in improved pathology and muscle function in mouse models of muscular dystrophy. ${ }^{115,116}$ Additional research is needed to identify the role of selective NF- $\mathrm{KB}$ modulators and similar antiinflammatory interventions for DMD. ${ }^{117}$

Other potential anti-inflammatory therapies including $\mathrm{N}$-acetylcysteine, ${ }^{118}$ green tea extract, ${ }^{119}$ idebenone, ${ }^{120,121}$ melatonin, ${ }^{122,123}$ and pentoxifylline ${ }^{124}$ were previously tried for DMD, with inconclusive results. Newer agents including givinostat (NCT01761292), a histone deacetylase inhibitor; ${ }^{125}$ CAT1004 (NCT02439216), an oral molecule that inhibits activated NF-kB; and flavocoxid (NCT01335295), a blend of plant-derived flavonoids with anti-inflammatory activity, are currently under evaluation as potential disease-modifying treatment for DMD. ${ }^{126,127}$

\section{Antifibrotic drugs}

Elevated levels of TGF- $\beta$ in muscular dystrophies stimulate fibrosis and impair muscle regeneration by blocking the activation of satellite cells. A number of antifibrotic agents have been tested in murine models of muscular dystrophy, including losartan, an angiotensin II-type 1 receptor blocker that reduces the expression of TGF- $\beta .{ }^{128-130}$ Other potential fibrosis inhibitors include HT-100 (halofuginone), ${ }^{131}$ FG-3019, a monoclonal antibody to connective tissue growth factor, ${ }^{132}$ and targeted microRNAs; ${ }^{133,134}$ further clinical trials are pending.

\section{Muscle regeneration}

Myostatin is a negative regulator of muscle mass. Inhibition or blockade of endogenous myostatin offers a potential means to compensate for the severe muscle wasting that is common in many types of muscular dystrophies including DMD. A Phase I/II multicenter clinical trial using MYO-029, a myostatin blocking antibody for adult subjects with Becker muscular dystrophies and other dystrophies, demonstrated safety, but the study was not sufficiently powered for efficacy. ${ }^{74}$ Clinical trials using follistatin and other myostatin inhibitors including PF-06252616 (NCT02310764) and BMS-986089 (NCT02515669) are currently under way. ${ }^{127,135,136}$ As well, the therapeutic potential of insulin growth factor (NCT01207908) as a positive regulator of muscle development and regeneration was shown in the dystrophic mouse models, ${ }^{137}$ especially when combined with mesenchymal stromal cells. ${ }^{138,139}$ Due to its 
regeneration-enhancing mechanism, this combinational approach may have general applicability for other muscular dystrophies.

\section{Treatment of muscle ischemia}

Loss of dystrophin leads to displacement of neuronal nitric oxide synthase and reduction of muscle-derived nitric oxide to the microvasculature, resulting in functional muscle ischemia and further muscle injury. ${ }^{19}$ Strategies to increase blood flow include pharmaceutical inhibition of either phosphodiesterase-5 or ACE, induction of angiogenesis through delivery of vascular endothelial growth factor (VEGF), or downregulation of the VEGF decoy-receptor type 1 (VEGFR-1 or Flt-1). ${ }^{140,141}$ Despite initial promising results, ${ }^{142}$ clinical trials involving the use of tadalafil as disease-modifying treatment for DMD (NCT01865084 and 01070511) have recently been terminated due to a lack of demonstrated efficacy in slowing the decline of the 6MWT.

\section{Future therapeutic targets}

Given the limited success of exon skipping and other disease-modifying treatment for DMD to date, future clinical trials may include pharmacogenomics consideration, highthroughput screening, mRNA or genome-wide association studies, and additional translational research from animal models to identify other potential therapeutic options. ${ }^{78,143}$ Current challenges including T-cell-mediated immune response or antibodies to generated dystrophin, limited evidence of dystrophin production in muscle biopsies, inefficient methods of drug delivery to the whole body, and inconsistent efficacy will need to be resolved. The long-term safety and tolerability of ataluren, eteplirsen, and drisapersen will await additional monitoring and further Food and Drug Administration review. Currently, all three treatments have not been formally approved by the Food and Drug Administration due to insufficient data on long-term efficacy. Patient-focused perspective including health-related quality of life, satisfaction with care, acceptability or adherence to treatment, and participation in clinical trials will need to be considered in further collaborative research among neuromuscular disease registries and academic centers.

Correction of the genetic defect using engineered nucleases holds promise for the treatment of DMD. ${ }^{144-146}$ Recent studies on $m d x$ mouse showed functional recovery in treated mice with RNA-guided clustered regularly interspaced short palindromic repeats-Cas9 endonucleases delivered by adeno-associated virus, with reversal of dystrophic changes in skeletal muscle fibers and cardiomyocytes, as well as in muscle satellite cells. ${ }^{144,147,148}$ The same genome editing technology can potentially benefit the majority of individuals with DMD, especially when combined with newborn screening. ${ }^{148}$ As well, a new clinical trial involving the study of VBP15, an oral glucocorticoid analog with antiinflammatory properties and improved side-effect profile, is scheduled to begin later this year for ambulatory boys with DMD. ${ }^{149}$

\section{Conclusion}

The pathogenesis affecting DMD is complex; multiple interventions targeting different disease processes are needed. Early recognition and precise genetic diagnosis will allow for individualized therapeutic options for DMD. ${ }^{150}$ Even though there is presently no cure, respiratory intervention and other supportive strategies as outlined in the current standard of care for DMD have led to improved survival and better health-related quality of life for many affected individuals. New emerging treatments will depend on the appropriate use of clinical end points and sensitive surrogate outcome measures such as muscle MRI and circulating biomarkers to detect meaningful changes in disease progression. ${ }^{151-153}$

\section{Disclosure}

The author reports no conflicts of interest in this work.

\section{References}

1. Emery AE. Population frequencies of inherited neuromuscular diseases a world survey. Neuromuscul Disord. 1991;1(1):19-29.

2. Mah JK, Korngut L, Dykeman J, Day L, Pringsheim T, Jette N. A systematic review and meta-analysis on the epidemiology of Duchenne and Becker muscular dystrophy. Neuromuscul Disord. 2014;24(6): 482-491.

3. Bushby K, Finkel R, Birnkrant DJ, et al. Diagnosis and management of Duchenne muscular dystrophy, part 1: diagnosis, and pharmacological and psychosocial management. Lancet Neurol. 2010;9(1):77-93.

4. Pane M, Lombardo ME, Alfieri P, et al. Attention deficit hyperactivity disorder and cognitive function in Duchenne muscular dystrophy: phenotype-genotype correlation. J Pediatr. 2012;161(4): 705.e1-709.e1.

5. McDonald CM, Henricson EK, Abresch RT, et al. The cooperative international neuromuscular research group Duchenne natural history study a longitudinal investigation in the era of glucocorticoid therapy: design of protocol and the methods used. Muscle Nerve. 2013;48(1): $32-54$.

6. Kieny P, Chollet S, Delalande P, et al. Evolution of life expectancy of patients with Duchenne muscular dystrophy at AFM Yolaine de Kepper Centre between 1981 and 2011. Ann Phys Rehabil Med. 2013; 56(6):443-454

7. Hoffman EP, Brown RH, Kunkel LM. Dystrophin: the protein product of the Duchenne muscular dystrophy locus. Cell. 1987;51(6): 919-928.

8. Koenig M, Monaco AP, Kunkel LM. The complete sequence of dystrophin predicts a rod-shaped cytoskeletal protein. Cell. 1988;53(2) 219-228.

9. Bladen CL, Salgado D, Monges S, et al. The TREAT-NMD DMD Global Database: Analysis of More than 7,000 Duchenne Muscular Dystrophy Mutations. Hum Mutat. 2015;36(4):395. 
10. Aartsma-Rus A, Van Deutekom JC, Fokkema IF, Van Ommen GJ, Den Dunnen JT. Entries in the Leiden Duchenne muscular dystrophy mutation database: an overview of mutation types and paradoxical cases that confirm the reading-frame rule. Muscle Nerve. 2006;34(2):135-144.

11. Mah JK, Selby K, Campbell C, et al. A population-based study of dystrophin mutations in Canada. Can J Neurol Sci. 2011;38(3):465-474.

12. Nallamilli BR, Ankala A, Hegde M. Molecular diagnosis of Duchenne muscular dystrophy. Curr Protoc Hum Genet. 2014;83: 9.25.1-9.25.29.

13. Koenig M, Beggs AH, Moyer M, et al. The molecular basis for Duchenne versus Becker muscular dystrophy: correlation of severity with type of deletion. Am J Hum Genet. 1989;45(4):498-506.

14. Monaco AP, Bertelson CJ, Liechti-Gallati S, Moser H, Kunkel LM. An explanation for the phenotypic differences between patients bearing partial deletions of the DMD locus. Genomics. 1988;2(1):90-95.

15. Bladen CL, Rafferty K, Straub V, et al. The TREAT-NMD Duchenne muscular dystrophy registries: conception, design, and utilization by industry and academia. Hum Mutat. 2013;34(11):1449-1457.

16. Pegoraro E, Hoffman EP, Piva L, et al. SPP1 genotype is a determinant of disease severity in Duchenne muscular dystrophy. Neurology. 2011;76(3):219-226.

17. Barp A, Bello L, Politano L, et al. Genetic modifiers of Duchenne muscular dystrophy and dilated cardiomyopathy. PLoS One. 2015; 10(10): 0141240

18. Bello L, Kesari A, Gordish-Dressman H, et al. Genetic modifiers of ambulation in the cooperative international neuromuscular research group Duchenne natural history study. Ann Neurol. 2015;77(4): 684-696.

19. Muntoni F, Torelli S, Ferlini A. Dystrophin and mutations: one gene, several proteins, multiple phenotypes. Lancet Neurol. 2003;2(12): 731-740.

20. Wallace GQ, McNally EM. Mechanisms of muscle degeneration, regeneration, and repair in the muscular dystrophies. Annu Rev Physiol. 2009;71:37-57.

21. Allen DG, Gervasio OL, Yeung EW, Whitehead NP. Calcium and the damage pathways in muscular dystrophy. Can J Physiol Pharmacol. 2010;88(2):83-91.

22. Gumerson JD, Michele DE. The dystrophin-glycoprotein complex in the prevention of muscle damage. J Biomed Biotechnol. 2011;2011: 210797.

23. Thomas GD. Functional muscle ischemia in Duchenne and Becker muscular dystrophy. Front Physiol. 2013;4:381.

24. Shin J, Tajrishi MM, Ogura Y, Kumar A. Wasting mechanisms in muscular dystrophy. Int J Biochem Cell Biol. 2013;45(10):2266-2279.

25. van Ruiten HJ, Straub V, Bushby K, Guglieri M. Improving recognition of Duchenne muscular dystrophy: a retrospective case note review. Arch Dis Child. 2014;99(12):1074-1077.

26. Hedge MR, Chin ELH, Mulle JG, Okou DT, Warren ST, Zwick ME. Microarray-based mutation detection in the dystrophin gene. Hum Mutat. 2008;29(9):1091-1099.

27. Takeshima Y, Yagi M, Okizuka Y, et al. Mutation spectrum of the dystrophin gene in 442 Duchenne/Becker muscular dystrophy cases from one Japanese referral center. J Hum Genet. 2010;55(6):379-388.

28. Aartsma-Rus A, Ginjaar IB, Bushby K. The importance of genetic diagnosis for Duchenne muscular dystrophy. J Med Genet. 2016;53(3): $145-151$.

29. Mah JK, Thannhauser JE, MacNeil DA, Dewey D. Being the lifeline: the parent experience of caring for a child with neuromuscular disease on home mechanical ventilation. Neuromuscul Disord. 2008;18(12): 983-988.

30. Nereo NE, Fee RJ, Hinton VJ. Parental stress in mothers of boys with Duchenne muscular dystrophy. J Pediatr Psychol. 2003;28(7): 473-484.

31. Samson A, Tomiak E, Dimillo J, et al. The lived experience of hope among parents of a child with Duchenne muscular dystrophy: perceiving the human being beyond the illness. Chronic Illn. 2009;5(2): $103-114$.
32. Pangalila RF, van den Bos GA, Stam HJ, van Exel NJ, Brouwer WB, Roebroeck ME. Subjective caregiver burden of parents of adults with Duchenne muscular dystrophy. Disabil Rehabil. 2012;34(12): 988-996.

33. McMillan HJ, Campbell C, Mah JK; Canadian Paediatric Neuromuscular Group. Duchenne muscular dystrophy: Canadian paediatric neuromuscular physicians survey. Can J Neurol Sci. 2010;37(2): 195-205.

34. Soltanzadeh P, Friez MJ, Dunn D, et al. Clinical and genetic characterization of manifesting carriers of DMD mutations. Neuromuscul Disord. 2010;20(8):499-504.

35. Bushby K, Finkel R, Birnkrant DJ, et al. Diagnosis and management of Duchenne muscular dystrophy, part 2: implementation of multidisciplinary care. Lancet Neurol. 2010;9(2):177-189.

36. Eagle M, Baudouin SV, Chandler C, Giddings DR, Bullock R, Bushby K. Survival in Duchenne muscular dystrophy: improvements in life expectancy since 1967 and the impact of home nocturnal ventilation. Neuromuscul Disord. 2002;12(10):926-929.

37. Center for Disease Control. Survival of males diagnosed with Duchenne/ Becker muscular dystrophy (DBMD) by years of birth - muscular dystrophy surveillance tracking and research network. MMWR. 2009; 58(40):1119-1122.

38. Villanova M, Brancalion B, Mehta AD. Duchenne muscular dystrophy: life prolongation by noninvasive ventilatory support. Am J Phys Med Rehabil. 2014;93(7):595-599.

39. Bushby K, Muntoni F, Urtizberea A, Hughes R, Griggs R. Report on the 124th ENMC international workshop. Treatment of Duchenne muscular dystrophy; defining the gold standards of management in the use of corticosteroids. 2-4 April 2004, Naarden, the Netherlands. Neuromuscul Disord. 2004;14(8-9):526-534.

40. Moxley RT, Ashwal S, Pandya S, et al; Quality Standards Subcommittee of the American Academy of Neurology; Practice Committee of the Child Neurology Society. Practice parameter: corticosteroid treatment of Duchenne dystrophy: report of the quality standards subcommittee of the American Academy of Neurology and the practice committee of the Child Neurology Society. Neurology. 2005; 64(1):13-20.

41. Mendell JR, Moxley RT, Griggs RC, et al. Randomized, double-blind six-month trial of prednisone in Duchenne's muscular dystrophy. NEngl J Med. 1989;320(24):1592-1597.

42. Griggs RC, Moxley RT, Mendell JR, et al. Prednisone in Duchenne dystrophy. A randomized, controlled trial defining the time course and dose response. Clinical investigation of Duchenne dystrophy group. Arch Neurol. 1991;48(4):383-388.

43. Biggar WD, Gingras M, Fehlings DL, Harris VA, Steele CA. Deflazacort treatment of Duchenne muscular dystrophy. J Pediatr. 2001; 138(1):45-50.

44. Schara U, Mortier J, Mortier W. Long-term steroid therapy in Duchenne muscular dystrophy-positive results versus side effects. $J$ Clin Neuromuscul Dis. 2001;2(4):179-183.

45. Kinali M, Main M, Eliahoo J, et al. Predictive factors for the development of scoliosis in Duchenne muscular dystrophy. Eur J Paediatr Neurol. 2007;11(3):160-166.

46. Markham LW, Kinnett K, Wong BL, Woodrow Benson D, Cripe LH. Corticosteroid treatment retards development of ventricular dysfunction in Duchenne muscular dystrophy. Neuromuscul Disord. 2008; 18(5):365-370

47. Henricson EK, Abresch RT, Cnaan A, et al. The Cooperative International Neuromuscular Research Group Duchenne natural history study: glucocorticoid treatment preserves clinically meaningful functional milestones and reduces rate of disease progression as measured by manual muscle testing and other commonly used clinical trial outcome measures. Muscle Nerve. 2013;48(1):55-67.

48. Pane M, Fanelli L, Mazzone ES, et al. Benefits of glucocorticoids in non-ambulant boys/men with Duchenne muscular dystrophy: a multicentric longitudinal study using the performance of upper limb test. Neuromuscul Disord. 2015;25(10):749-753. 
49. Gloss D, Moxley RT, Ashwal S, Oskoui M. Practice guideline update summary: corticosteroid treatment of Duchenne muscular dystrophy: report of the guideline development subcommittee of the American Academy of Neurology. Neurology. 2016;86(5):465-472.

50. Angelini C, Peterle E. Old and new therapeutic developments in steroid treatment in Duchenne muscular dystrophy. Acta Myol. 2012; 31(1):9-15.

51. McAdam LC, Mayo AL, Alman BA, Biggar WD. The Canadian experience with long-term deflazacort treatment in Duchenne muscular dystrophy. Acta Myol. 2012;31(1):16-20.

52. Sbrocchi AM, Rauch F, Jacob P, et al. The use of intravenous bisphosphonate therapy to treat vertebral fractures due to osteoporosis among boys with Duchenne muscular dystrophy. Osteoporos Int. 2012; 23(11):2703-2711.

53. Houston C, Mathews K, Shibli-Rahhal A. Bone density and alendronate effects in Duchenne muscular dystrophy patients. Muscle Nerve. 2014; 49(4):506-511.

54. Buckner JL, Bowden SA, Mahan JD. Optimizing bone health in Duchenne muscular dystrophy. Int J Endocrinol. 2015;2015:928385.

55. American Academy of Pediatrics Section on Cardiology and Cardiac Surgery. Cardiovascular health supervision for individuals affected by Duchenne or Becker muscular dystrophy. Pediatrics. 2005;116(6): 1569-1573.

56. Judge DP, Kass DA, Thompson WR, Wagner KR. Pathophysiology and therapy of cardiac dysfunction in Duchenne muscular dystrophy. Am J Cardiovasc Drugs. 2011;11(5):287-294.

57. Passamano L, Taglia A, Palladino A, et al. Improvement of survival in Duchenne muscular dystrophy: retrospective analysis of 835 patients. Acta Myol. 2012;31(2):121-125.

58. Spurney CF. Cardiomyopathy of Duchenne muscular dystrophy: current understanding and future directions. Muscle Nerve. 2011;44(1):8-19.

59. Bilchick KC, Salerno M, Plitt D, et al. Prevalence and distribution of regional scar in dysfunctional myocardial segments in Duchenne muscular dystrophy. J Cardiovasc Magn Reson. 2011;13(1):20.

60. Romfh A, McNally EM. Cardiac assessment in Duchenne and Becker muscular dystrophies. Curr Heart Fail Rep. 2010;7(4):212-218.

61. Nigro G, Comi LI, Politano L, Bain RJ. The incidence and evolution of cardiomyopathy in Duchenne muscular dystrophy. Int J Cardiol. 1990;26(3):271-277.

62. Spurney C, Shimizu R, Morgenroth LP, et al. Cooperative international neuromuscular research group Duchenne natural history study demonstrates insufficient diagnosis and treatment of cardiomyopathy in Duchenne muscular dystrophy. Muscle Nerve. 2014;50(2):250-256.

63. McNally EM, Kaltman JR, Benson DW, et al. Contemporary cardiac issues in Duchenne muscular dystrophy. Working group of the national heart, lung, and blood institute in collaboration with parent project muscular dystrophy. Circulation. 2015;131(18):1590-1598.

64. Hor KN, Taylor MD, Al-Khalidi HR, et al. Prevalence and distribution of late gadolinium enhancement in a large population of patients with Duchenne muscular dystrophy: effect of age and left ventricular systolic function. J Cardiovasc Magn Reson. 2013;15:107.

65. Raman SV, Hor KN, Mazur W, et al. Eplerenone for early cardiomyopathy in Duchenne muscular dystrophy: a randomised, double-blind, placebo-controlled trial. Lancet Neurol. 2015;14(2):153-161.

66. Finder JD, Birnkrant D, Carl J, et al. Respiratory care of the patient with Duchenne muscular dystrophy: ATS consensus statement. Am J Respir Crit Care Med. 2004;170(4):456-465.

67. Birnkrant DJ, Bushby KM, Amin RS, et al. The respiratory management of patients with Duchenne muscular dystrophy: a DMD care considerations working group specialty article. Pediatr Pulmonol. 2010;45(8): 739-748

68. Bach JR, Martinez D. Duchenne muscular dystrophy: continuous noninvasive ventilatory support prolongs survival. Respir Care. 2011;56(6): 744-750.

69. McKim DA, Katz SL, Barrowman N, Ni A, LeBlanc C. Lung volume recruitment slows pulmonary function decline in Duchenne muscular dystrophy. Arch Phys Med Rehabil. 2012;93(7):1117-1122.
70. Bach JR, Sinquee DM, Saporito LR, Botticello AL. Efficacy of mechanical insufflation-exsufflation in extubating unweanable subjects with restrictive pulmonary disorders. Respir Care. 2015;60(4):477-483.

71. LoMauro A, D’Angelo MG, Aliverti A. Assessment and management of respiratory function in patients with Duchenne muscular dystrophy: current and emerging options. Ther Clin Risk Manag. 2015;11: $1475-1488$.

72. Hsu JD, Quinlivan R. Scoliosis in Duchenne muscular dystrophy (DMD). Neuromuscul Disord. 2013;23(8):611-617.

73. Davidson ZE, Truby H. A review of nutrition in Duchenne muscular dystrophy. J Hum Nutr Diet. 2009;22(5):383-393.

74. Wagner KR. Approaching a new age in DMD treatment. Neurotherapeutics. 2008;5(4):583-591.

75. Mercuri E, Muntoni F. Muscular dystrophy: new challenges and review of the current clinical trials. Curr Opin Pediatr. 2013;25(6):701-707.

76. Shieh PB. Duchenne muscular dystrophy: clinical trials and emerging tribulations. Curr Opin Neurol. 2015;28(5):542-546.

77. Konieczny P, Swiderski K, Chamberlain JS. Gene and cell-mediated therapies for muscular dystrophy. Muscle Nerve. 2013;47(5):649-663.

78. Bertoni C. Emerging gene editing strategies for Duchenne muscular dystrophy targeting stem cells. Front Physiol. 2014;5:148.

79. Al-Zaidy S, Rodino-Klapac L, Mendell JR. Gene therapy for muscular dystrophy: moving the field forward. Pediatr Neurol. 2014;51(5): 607-618.

80. Malik V, Rodino-Klapac LR, Mendell JR. Emerging drugs for Duchenne muscular dystrophy. Expert Opin Emerg Drugs. 2012;17(2): 261-277.

81. Marshall JL, Crosbie-Watson RH. Sarcospan: a small protein with large potential for Duchenne muscular dystrophy. Skelet Muscle. 2013;3(1):1.

82. De Paepe B, De Bleecker JL. Cytokines and chemokines as regulators of skeletal muscle inflammation: presenting the case of Duchenne muscular dystrophy. Mediators Inflamm. 2013;2013(2-3):540370.

83. Motohashi N, Asakura A. Muscle satellite cell heterogeneity and selfrenewal. Front Cell Dev Biol. 2014;2:1.

84. Shin JH, Pan X, Hakim CH, et al. Microdystrophin ameliorates muscular dystrophy in the canine model of duchenne muscular dystrophy. Mol Ther. 2013;21(4):750-757.

85. Mendell JR, Campbell K, Rodino-Klapac L, et al. Dystrophin immunity in Duchenne's muscular dystrophy. $N$ Engl J Med. 2010;363(15): 1429-1437.

86. Okada T, Takeda S. Current challenges and future directions in recombinant aav-mediated gene therapy of Duchenne muscular dystrophy. Pharmaceuticals (Basel). 2013;6(7):813-836.

87. van Deutekom JC, Janson AA, Ginjaar IB, et al. Local dystrophin restoration with antisense oligonucleotide PRO051. $N$ Engl J Med. 2007;357(26):2677-2686.

88. Goemans NM, Tulinius M, van den Akker JT, et al. Systemic administration of PRO051 in Duchenne's muscular dystrophy. $N$ Engl J Med. 2011;364(16):1513-1522.

89. Flanigan KM, Voit T, Rosales XQ, et al. Pharmacokinetics and safety of single doses of drisapersen in non-ambulant subjects with Duchenne muscular dystrophy: results of a double-blind randomized clinical trial. Neuromuscul Disord. 2014;24(1):16-24.

90. Goemans N, Campbell C, Kraus JE, et al. Drisapersen efficacy and safety in Duchenne muscular dystrophy: results of a Phase III, randomized, double-blind, placebo-controlled trial (study DMD114044). In: World Muscle Society Congress [abstract]; Asilomar, CA, USA; October 1-5, 2013.

91. Voit T, Topaloglu H, Straub V, et al. Safety and efficacy of drisapersen for the treatment of Duchenne muscular dystrophy (DEMAND II): an exploratory, randomised, placebo-controlled phase 2 study. Lancet Neurol. 2014;13(10):987-996.

92. Kinali M, Arechavala-Gomeza V, Feng L, et al. Local restoration of dystrophin expression with the morpholino oligomer AVI-4658 in duchenne muscular dystrophy: a single-blind, placebo-controlled, dose-escalation, proof-of-concept study. Lancet Neurol. 2009;8(10):918-928. 
93. Cirak S, Arechavala-Gomeza V, Guglieri M, et al. Exon skipping and dystrophin restoration in patients with Duchenne muscular dystrophy after systemic phosphorodiamidate morpholino oligomer treatment: an open-label, phase 2, dose-escalation study. Lancet. 2011; 378(9791):595-605.

94. Mendell JR, Rodino-Klapac LR, Sahenk Z, et al. Eteplirsen for the treatment of Duchenne muscular dystrophy. Ann Neurol. 2013;74(5): 637-647.

95. Mendell JR, Goemans N, Lowes LP, et al. Longitudinal effect of eteplirsen versus historical control on ambulation in Duchenne muscular dystrophy. Ann Neurol. 2016;79(2):257-271.

96. Malueka RG, Dwianingsih EK, Yagi M, et al. Phosphorothioate modification of chimeric 2'-o-methyl RNA/ethylene-bridged nucleic acid oligonucleotides increases dystrophin exon 45 skipping capability and reduces cytotoxicity. Kobe J Med Sci. 2015;60(4):E86-E94.

97. Yu X, Bao B, Echigoya Y, Yokota T. Dystrophin-deficient large animal models: translational research and exon skipping. Am J Transl Res. 2015;7(8):1314-1331.

98. Wagner KR, Hamed S, Hadley DW, et al. Gentamicin treatment of Duchenne and Becker muscular dystrophy due to nonsense mutations. Ann Neurol. 2001;49(6):706-711.

99. Politano L, Nigro G, Nigro V, et al. Gentamicin administration in Duchenne patients with premature stop codon. Preliminary results. Acta Myol. 2003;22(1):15-21.

100. Malik V, Rodino-Klapac LR, Viollet L, et al. Gentamicin-induced readthrough of stop codons in Duchenne muscular dystrophy. Ann Neurol. 2010;67(6):771-780.

101. Welch EM, Barton ER, Zhuo J, et al. PTC124 targets genetic disorders caused by nonsense mutations. Nature. 2007;447(7140):87-91.

102. Finkel RS, Flanigan KM, Wong B, et al. Phase $2 \mathrm{a}$ study of atalurenmediated dystrophin production in patients with nonsense mutation Duchenne muscular dystrophy. PLoS One. 2013;8(12):e81302.

103. Bushby K, Finkel R, Wong B, et al. Ataluren treatment of patients with nonsense mutation dystrophinopathy. Muscle Nerve. 2014; 50(4):477-487.

104. Haas M, Vlcek V, Balabanov P, et al. European medicines agency review of Ataluren for the treatment of ambulant patients aged 5 years and older with Duchenne muscular dystrophy resulting from a nonsense mutation in the dystrophin gene. Neuromuscul Disord. 2015; 25(1):5-13.

105. Karijolich J, Yu YT. Therapeutic suppression of premature termination codons: mechanisms and clinical considerations (review). Int $J \mathrm{Mol}$ Med. 2014;34(2):355-362.

106. Asakura A. Skeletal muscle-derived hematopoietic stem cells: muscular dystrophy therapy by bone marrow transplantation. J Stem Cell Res Ther. 2012;Suppl 11:1-5.

107. Cossu G, Previtali SC, Napolitano S, et al. Intra-arterial transplantation of hla-matched donor mesoangioblasts in Duchenne muscular dystrophy. EMBO Mol Med. 2015;7(12):1513-1528.

108. Briggs D, Morgan JE. Recent progress in satellite cell/myoblast engraftment - relevance for therapy. FEBS J. 2013;280(17): 4281-4293.

109. Tinsley JM, Fairclough RJ, Storer R, et al. Daily treatment with SMTC1100, a novel small molecule utrophin upregulator, dramatically reduces the dystrophic symptoms in the mdx mouse. PLoS One. 2011;6(5):e19189.

110. Heller KN, Montgomery CL, Janssen PM, Clark KR, Mendell JR, Rodino-Klapac LR. AAV-mediated overexpression of human $\alpha 7$ integrin leads to histological and functional improvement in dystrophic mice. Mol Ther. 2013;21(3):520-525.

111. Amenta AR, Yilmaz A, Bogdanovich S, et al. Biglycan recruits utrophin to the sarcolemma and counters dystrophic pathology in $\mathrm{mdx}$ mice. Proc Natl Acad Sci U S A. 2011;108(2):762-767.

112. Marshall JL, Kwok Y, McMorran BJ, Baum LG, CrosbieWatson $\mathrm{RH}$. The potential of sarcospan in adhesion complex replacement therapeutics for the treatment of muscular dystrophy. FEBS $J$. 2013;280(17):4210-4229.
113. Guiraud S, Squire SE, Edwards B, et al. Second-generation compound for the modulation of utrophin in the therapy of DMD. Hum Mol Genet. 2015;24(15):4212-4224.

114. Acharyya S, Villalta SA, Bakkar N, et al. Interplay of IKK/NFKappaB signaling in macrophages and myofibers promotes muscle degeneration in Duchenne muscular dystrophy. J Clin Invest. 2007; 117(4):889-901.

115. Peterson JM, Kline W, Canan BD, et al. Peptide-based inhibition of NF- $\kappa B$ rescues diaphragm muscle contractile dysfunction in a murine model of Duchenne muscular dystrophy. Mol Med. 2011; 17(5-6):508-515.

116. Delfín DA, Xu Y, Peterson JM, Guttridge DC, Rafael-Fortney JA, Janssen PM. Improvement of cardiac contractile function by peptidebased inhibition of NF- $\mathrm{\kappa B}$ in the utrophin/dystrophin-deficient murine model of muscular dystrophy. J Transl Med. 2011;9:68.

117. Urso ML. Anti-inflammatory interventions and skeletal muscle injury: benefit or detriment? J Appl Physiol. 2013;115(6):920-928.

118. Whitehead NP, Pham C, Gervasio OL, Allen DG. N-Acetylcysteine ameliorates skeletal muscle pathophysiology in $\mathrm{mdx}$ mice. J Physiol. 2008;586(7):2003-2014.

119. Evans NP, Call JA, Bassaganya-Riera J, Robertson JL, Grange RW. Green tea extract decreases muscle pathology and NF-kappa B immunostaining in regenerating muscle fibers of mdx mice. Clin Nutr. 2010;29(3):391-398.

120. Buyse GM, Van der Mieren G, Erb M, et al. Long-term blinded placebo-controlled study of SNT-MC17/idebenone in the dystrophin deficient mdx mouse: cardiac protection and improved exercise performance. Eur Heart J. 2009;30(1):116-124.

121. Buyse GM, Goemans N, van den Hauwe M, et al. Idebenone as a novel, therapeutic approach for Duchenne muscular dystrophy: results from a 12 month, double-blind, randomized placebo-controlled trial. Neuromuscul Disord. 2011;21(6):396-405.

122. Hibaoui Y, Reutenauer-Patte J, Patthey-Vuadens O, Ruegg UT, Dorchies OM. Melatonin improves muscle function of the dystrophic mdx $5 \mathrm{cv}$ mouse, a model for Duchenne muscular dystrophy. JPineal Res. 2011;51(2):163-171.

123. Chahbouni M, Escames G, López LC, et al. Melatonin treatment counteracts the hyperoxidative status in erythrocytes of patients suffering from Duchenne muscular dystrophy. Clin Biochem. 2011; 44(10-11):853-858.

124. Escolar DM, Zimmerman A, Bertorini T, et al. Pentoxifylline as a rescue treatment for DMD: a randomized double-blind clinical trial. Neurology. 2012;78(12):904-913.

125. Consalvi S, Mozzetta C, Bettica P, et al. Preclinical studies in the mdx mouse model of Duchenne muscular dystrophy with the histone deacetylase inhibitor givinostat. Mol Med. 2013;19:79-87.

126. Wyatt EJ, Sweeney HL, McNally EM. Meeting report: new directions in the biology and disease of skeletal muscle 2014. J Neuromuscul Dis. 2014;1(2):197-206.

127. Heslop E, Csimma C, Straub V, et al. The TREAT-NMD advisory committee for therapeutics (TACT): an innovative de-risking model to foster orphan drug development. Orphanet J Rare Dis. 2015;10:49.

128. Cohn RD, van Erp C, Habashi JP, et al. Angiotensin II type 1 receptor blockade attenuates TGF-beta-induced failure of muscle regeneration in multiple myopathic states. Nat Med. 2007;13(2):204-210.

129. Spurney CF, Sali A, Guerron AD, et al. Losartan decreases cardiac muscle fibrosis and improves cardiac function in dystrophin-deficient mdx mice. J Cardiovasc Pharmacol Ther. 2011;16(1):87-95.

130. Bish LT, Yarchoan M, Sleeper MM, et al. Chronic losartan administration reduces mortality and preserves cardiac but not skeletal muscle function in dystrophic mice. PLoS One. 2011;6(6):e20856.

131. Bodanovsky A, Guttman N, Barzilai-Tutsch H, et al. Halofuginone improves muscle-cell survival in muscular dystrophies. Biochim Biophys Acta. 2014;1843(7):1339-1347.

132. Kharraz Y, Guerra J, Pessina P, Serrano AL, Muñoz-Cánoves P. Understanding the process of fibrosis in Duchenne muscular dystrophy. Biomed Res Int. 2014;2014:965631. 
133. Cacchiarelli D, Martone J, Girardi E, et al. MicroRNAs involved in molecular circuitries relevant for the Duchenne muscular dystrophy pathogenesis are controlled by the dystrophin/nNOS pathway. Cell Metab. 2010;12(4):341-351.

134. Twayana S, Legnini I, Cesana M, Cacchiarelli D, Morlando M, Bozzoni I. Biogenesis and function of non-coding RNAs in muscle differentiation and in Duchenne muscular dystrophy. Biochem Soc Trans. 2013;41(4):844-849.

135. Rodino-Klapac LR, Janssen PM, Shontz KM, et al. Micro-dystrophin and follistatin co-delivery restores muscle function in aged DMD model. Hum Mol Genet. 2013;22(24):4929-4937.

136. Kainulainen H, Papaioannou KG, Silvennoinen M, et al. Myostatin/ activin blocking combined with exercise reconditions skeletal muscle expression profile of mdx mice. Mol Cell Endocrinol. 2015; 399:131-142.

137. Song YH, Song JL, Delafontaine P, Godard MP. The therapeutic potential of IGF-I in skeletal muscle repair. Trends Endocrinol Metab. 2013;24(6):310-319.

138. Schertzer JD, van der Poel C, Shavlakadze T, Grounds MD, Lynch GS. Muscle-specific overexpression of IGF-I improves E-C coupling in skeletal muscle fibers from dystrophic mdx mice. Am J Physiol Cell Physiol. 2008;294(1):C161-C168.

139. Secco M, Bueno C, Vieira NM, et al. Systemic delivery of human mesenchymal stromal cells combined with IGF-1 enhances muscle functional recovery in LAMA2 dy/2j dystrophic mice. Stem Cell Rev. 2013;9(1):93-109.

140. Percival JM, Adamo CM, Beavo JA, Froehner SC. Evaluation of the therapeutic utility of phosphodiesterase $5 \mathrm{~A}$ inhibition in the mdx mouse model of Duchenne muscular dystrophy. Handb Exp Pharmacol. 2011;204:323-344.

141. Ennen JP, Verma M, Asakura A. Vascular-targeted therapies for Duchenne muscular dystrophy. Skelet Muscle. 2013;3(1):9.

142. Nelson MD, Rader F, Tang X, et al. PDE5 inhibition alleviates functional muscle ischemia in boys with Duchenne muscular dystrophy Neurology. 2014;82(23):2085-2091.
143. Bertoni TJ, Magh AS, Bertoni C. High throughput screening in Duchenne muscular dystrophy: from drug discovery to functional genomics. Biology (Basel). 2014;3(4):752-780.

144. Long C, Amoasii L, Mireault AA, et al. Postnatal genome editing partially restores dystrophin expression in a mouse model of muscular dystrophy. Science. 2016;351(6271):400-403.

145. Maggio I, Stefanucci L, Janssen JM, et al. Selection-free gene repair after adenoviral vector transduction of designer nucleases: rescue of dystrophin synthesis in DMD muscle cell populations. Nucleic Acids Res. 2016;44(3):1449-1470.

146. Nelson CE, Hakim CH, Ousterout DG, et al. In vivo genome editing improves muscle function in a mouse model of Duchenne muscular dystrophy. Science. 2016;351(6271):403-407.

147. Ousterout DG, Kabadi AM, Thakore PI, Majoros WH, Reddy TE, Gersbach CA. Multiplex CRISPR/cas9-based genome editing for correction of dystrophin mutations that cause Duchenne muscular dystrophy. Nat Commun. 2015;6:6244.

148. Mendell JR, Rodino-Klapac LR. CRISPR/Cas9 treatment for Duchenne muscular dystrophy. Cell Res. 2016;26(5):513-514.

149. Heier CR, Damsker JM, Yu Q, et al. VBP15, a novel anti-inflammatory and membrane-stabilizer, improves muscular dystrophy without side effects. EMBO Mol Med. 2013;5(10):1569-1585.

150. Strehle EM, Straub V. Recent advances in the management of Duchenne muscular dystrophy. Arch Dis Child. 2015;100(12):1173-1177.

151. Vohra RS, Lott D, Mathur S, et al. Magnetic resonance assessment of hypertrophic and pseudo-hypertrophic changes in lower leg muscles of boys with Duchenne muscular dystrophy and their relationship to functional measurements. PLoS One. 2015;10(6):e0128915.

152. Hathout Y, Seol H, Han MH, Zhang A, Brown KJ, Hoffman EP Clinical utility of serum biomarkers in Duchenne muscular dystrophy. Clin Proteomics. 2016;13:9.

153. Merlini L, Sabatelli P. Improving clinical trial design for Duchenne muscular dystrophy. BMC Neurol. 2015;15:153.
Neuropsychiatric Disease and Treatment

\section{Publish your work in this journal}

Neuropsychiatric Disease and Treatment is an international, peerreviewed journal of clinical therapeutics and pharmacology focusing on concise rapid reporting of clinical or pre-clinical studies on a range of neuropsychiatric and neurological disorders. This journal is indexed on PubMed Central, the 'PsycINFO' database and CAS,

\section{Dovepress}

and is the official journal of The International Neuropsychiatric Association (INA). The manuscript management system is completely online and includes a very quick and fair peer-review system, which is all easy to use. Visit http://www.dovepress.com/testimonials.php to read real quotes from published authors. 